\title{
Right lower quadrant mass in a geriatric patient
}

\author{
J. Dupont ${ }^{1,2}$, A. Wolthuis ${ }^{3,4}$, K. Fagard ${ }^{1,2}$ \\ (1) Gerontology \& Geriatrics, Department of Public Health and Primary Care, KU Leuven, Leuven, Belgium ; (2) Department of Geriatric Medicine, UZ Leuven, Leuven, \\ Belgium ; (3) Abdominal Surgical Oncology, Department of Oncology, KU Leuven, Leuven, Belgium ; (4) Department of Abdominal Surgery, UZ Leuven, Leuven, Belgium.
}

\section{Case presentation}

An 88-year old man presented at the geriatric outpatient clinic with fatigue and weakness since three weeks. One month before presentation, he was admitted with erysipelas of the left lower leg. After discharge, he progressively developed loss of appetite and fatigue. The day before presentation, he noticed a painless swollen lump in his right lower quadrant (Figure 1A).

His medical history consisted of a transient ischemic attack, osteopenia, polymyalgia rheumatica treated with steroids, appendicular abscess treated with antibiotics and percutaneous drainage six years before, gallstones, chronic kidney disease, iron deficiency anemia and diverticulosis.

Laboratory findings showed an elevated CRP $(191.0 \mathrm{mg} / \mathrm{dL}[\leq 5.0 \mathrm{mg} / \mathrm{dL}])$ and mildly elevated liver function tests. A computed tomography scan was performed and showed a large abdominal mass (Figure 1B).

\section{What is your diagnosis?}

A large multilocular appendicular abscess was found with subcutaneous extension through the abdominal wall musculature and limited infestation of the iliopsoas muscle. Antibiotics were started, followed by local incision of the abscess with insertion of a drain under general anesthesia. The drain was removed after one week and antibiotics were continued up to two weeks. The patient recovered well and was discharged after three weeks with a recovered appetite and absence of biochemical inflammation.

Appendicular abscess or phlegmon occurs in $2-10 \%$ of patients with appendicitis (1). This presentation is mostly treated with a conservative approach, consisting of antibiotics, with or without percutaneous drainage (2). To date, there is no consensus whether or not to perform an interval appendectomy after conservative treatment. Recurrence in conservatively treated patients occurs in $7.4 \%$, and underlying cancer diagnoses have been described, mainly in adults over 40 years (3). Therefore, a colonoscopy and an interval appendectomy should be considered. In our patient, a colonoscopy and an elective laparoscopic interval appendectomy were performed two months after the current presentation. The endoscopic evaluation and pathological examination of
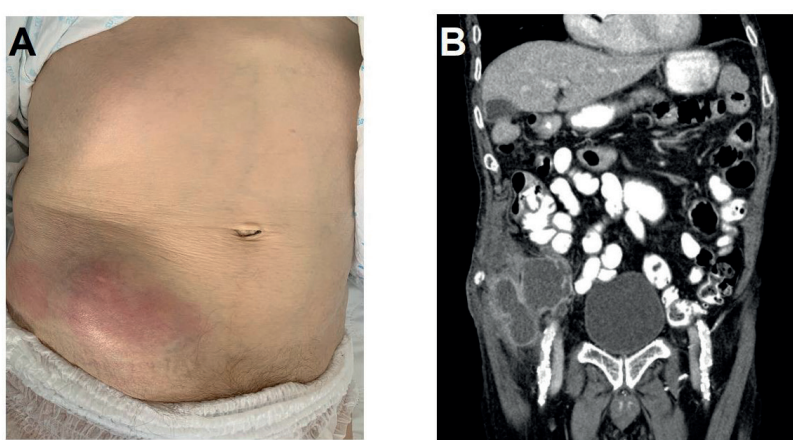

Figure 1. - A. Lump in the right lower quadrant ;

B. CT image showing a large abdominal mass.

the resection specimen showed no malignancy and the patient recovered well without complications.

\section{Grant support}

None

\section{Disclosures}

JD has received a fellowship (11A9320N) and travel support from Research Foundation Flanders (FWO), as well as a scholarship from Eli Lilly. AW and KF have nothing to disclose.

\section{Author contributions}

JD drafted the manuscript. AW and KF provided critical revisions of the manuscript. All authors read and approved the final version of this manuscript.

\section{Informed consent}

A written informed consent from the patient was obtained. Ethics Committee UZ/KULeuven gave its approval for publication of this manuscript (s64131).

\footnotetext{
Correspondence to : Dr. Katleen Fagard, Herestraat 49, BOX 7003, B-3000 Leuven, Belgium.

Email : katleen.fagard@uzleuven.be

Submission date : 29/05/2020

Acceptance date : 25/06/2020
} 
Key words : appendicitis, appendicular abscess, appendicular phlegmon, complicated appendicitis, older adult.

\section{References}

1. CHENG Y, XIONG X, LU J, WU S, ZHOU R, CHENG N. Early versus delayed appendicectomy for appendiceal phlegmon or abscess. Cochrane Database Syst. Rev. 2017, 6(6) : Cd011670.
2. GAVRIILIDIS P, DE'ANGELIS N, KATSANOS K, DI SAVERIO S. Acute Appendicectomy or Conservative Treatment for Complicated Appendicitis (Phlegmon or Abscess)? A Systematic Review by Updated Traditional and Cumulative Meta-Analysis. J. Clin. Med. Res. 2019, 11(1) : 56-64.

3. ANDERSSON RE, PETZOLD MG. Nonsurgical treatment of appendiceal abscess or phlegmon : a systematic review and meta-analysis. Ann. Surg. 2007, 246(5) : 741-8. 